\title{
Thymidylate Synthase and Drug Resistance
}

\author{
G.J. Peters, C.L. van der Wilt, B. van Triest, G. Codacci-Pisanelli, \\ P.G. Johnston, C.J. van Groeningen and H.M. Pinedo
}

Thymidylate synthase is an important target for both fluorinated pyrimidines and for new folate analogues. Resistance to 5-fluorouracil (5FU) can be related to insufficient inhibition of thymidylate synthase. The 5FUnucleotide FdUMP induces inhibition of thymidylate synthase which is enhanced and retained for longer in the presence of increased folate pools, for which leucovorin is a precursor. In a murine model system, 5FU treatment caused a 4-fold induction of thymidylate synthase levels which may have contributed to resistance. Addition of leucovorin to this treatment prevented this induction and increased the antitumour effect 2-3-fold. In the clinical setting, $5 \mathrm{FU}$ administration to patients resulted in approximately $50 \%$ inhibition of TS after $48 \mathrm{~h}$. The combination with leucovorin resulted in a more pronounced inhibition after $48 \mathrm{~h}$ (approximately $70 \%$ ). A significant relationship was observed with outcome of treatment; when thymidylate synthase levels were high and inhibition was low, no response was observed. A separate study showed that low thymidylate synthase levels appeared to be an independent prognostic factor for adjuvant therapy.

Key words: thymidylate synthase, 5-fluorouracil, leucovorin, resistance, folates, antifolates

Eurf Cancer, Vol. 31A, Nos 7/8, pp. 1299-1305, 1995

\section{INTRODUCTION}

IN THE LAST DECADE, evidence has accumulated suggesting that insufficient inhibition of thymidylate synthase may be a major resistance mechanism for 5-fluorouracil $(5 \mathrm{FU})[1,2]$, both in preclinical models and in patients [3-6]. In addition, the intrinsic cellular thymidylate synthase content may be an important prognostic parameter for chemotherapy with $5 \mathrm{FU}$-containing regimens $[5,7]$. Thymidylate synthase plays an essential role in the synthesis of DNA; it is the rate-limiting de novo enzyme for synthesis of thymine nucleotides, one of the precursors for DNA synthesis (Figure 1). Thymidylate synthase catalyses the methylation of dUMP to dTMP, for which 5,10-methylenetetrahydrofolate $\left(\mathrm{CH}_{2}\right.$-THF) is the limiting methyl donor. Usually the cellular concentrations of both substrates are too low $[6,8]$ to permit the enzyme to operate at its maximal rate. The active metabolite of 5FU, 5-fluoro- 2 '-deoxyuridine-5'-monophosphate (FdUMP), is a very potent inhibitor of thymidylate synthase and competes with dUMP for the same binding site on the enzyme.

This paper describes resistance to $5 F U$ in several model systems and in patients, in relation to thymidylate synthase content and inhibition, as well as the role of leucovorin in improving thymidylate synthase inhibition. Furthermore, the application of new immunological and molecular tools in the study of thymidylate synthase resistance will be discussed, as

Correspondence to G.J. Peters

G.J. Peters, C.L. van der Wilt, B. van Triest, G. Codacci-Pisanelli, C.J. van Groeningen and H.M. Pinedo are at the Department of Medical Oncology, Free University Hospital, PO Box 7057, 1007 MB Amsterdam, The Netherlands; and P.G. Johnston is at the National Cancer Institute-Navy Medical Oncology Branch, Building 8, Room 5101, Naval Hospital, Bethesda, Maryland 20889, U.S.A.

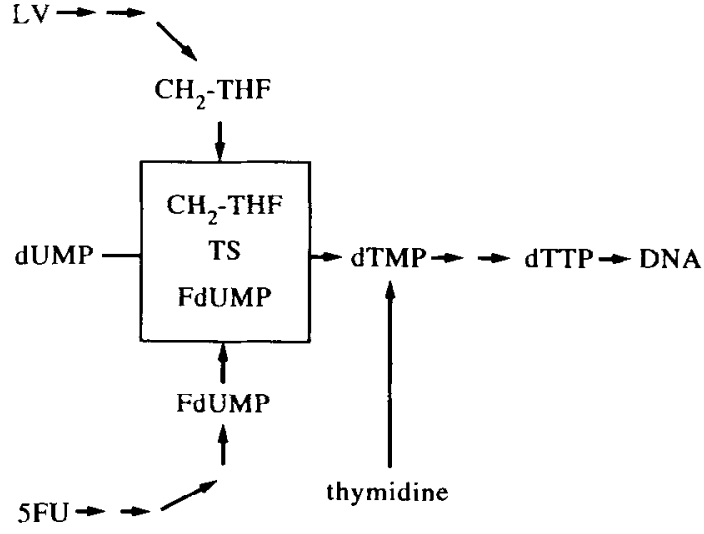

Figure 1. Mechanism of inhibition of thymidylate synthase (TS) by FdUMP, including the ternary complex formation. Intracellularly both SFU and leucovorin (LV) have to be metabolised to their active form FdUMP and $\mathrm{CH}_{2}$ THF, respectively. With thymidylate synthase, they form a ternary complex (represented by the box), preventing binding of the natural substrate dUMP to thymidylate synthase, and thus inhibiting its conversion to dTMP and sub sequently DNA synthesis. Thymidine can bypass thymidylate synthase inhibition by its direct conversion to dTMP.

well as approaches to the use of thymidylate synthase as a prognostic parameter.

\section{SFU RESISTANCE AND THYMIDYLATE SYNTHASE- GENERAL ASPECTS}

Inhibition of thymidylate synthase by FdUMP is mediated by the formation of a covalent ternary complex between FdUMP, thymidylate synthase and $\mathrm{CH}_{2}$-THF (Figure 1). Resistance to SFU has been related to insufficient inhibition of thymidylate 
synthase as well as a number of different mechanisms (Table 1). Alterations in the kinetics of thymidylate synthase with respect to dUMP and to FdUMP binding [1, 2, 9-12] have been reported to be associated with resistance. Treatment with $5 F U$ usually results in concentrations of FdUMP in cells and tissues exceeding 1000 -fold the minimal level required for thymidylate synthase inhibition [6, 13-15]. However, this inhibition of thymidylate synthase can be abrogated by a low ratio between FdUMP and the natural substrate dUMP [6].

The stability of the ternary complex is highly dependent on the availability of $\mathrm{CH}_{2}$-THF $[10,16]$ and on the rate of folate polyglutamylation. A decreased activity of folyl-polyglutamate synthetase has been associated with resistance to SFU [17]. In the absence of $\mathrm{CH}_{2}$-THF, an unstable binary complex is formed and, in this case, FdUMP acts as a weak inhibitor of thymidylate synthase. Leucovorin is an external source for $\mathrm{CH}_{2}$-THF. After administration (either orally or by intravenous (i.v.) infusion) leucovorin is readily distributed throughout the body [18]. After transfer across the cellular membrane, leucovorin has to be metabolised to $\mathrm{CH}_{2} \mathrm{THF}$. Although it has been reported that intermediates of this metabolic pathway can also support the formation of the ternary complex, $\mathrm{CH}_{2}$-THF is the best substrate [19].

Gene amplification of thymidylate synthase has been observed for 5-fluoro-2' deoxyuridine (FUdR)-resistant subcell lines [20]. Resistance was also observed in a cell line with a variant form of thymidylate synthase, encoded by a different gene, which has a reduced affinity for FdUMP and $\mathrm{CH}_{2}$-THF [12]. Evidence for gene amplification has also been obtained in one patient with colon cancer who developed resistance against 5FU treatment [21].

\section{FU-INDUCED INHIBITION OF THYMIDYLATE SYNTHASE IN MODEL SYSTEMS}

The potentiating effect of leucovorin on SFU therapy has been shown in in vitro [22] and in vivo models [14,23] and also in patients $[18,22]$. The thymidylate synthase inhibition that

\section{Table 1. Mechanisms of resistance to $5 F U$}

A. Decreased accumulation of activated metabolites

a. Decreased activation of $5 F U$

b. Increased inactivation of $5 \mathrm{FU}$

c. Increased inactivation of 5FU-nucleotides

B. Target-associated resistance

a. Decreased RNA effect

b. Altered effect on thymidylate synthase - aberrant enzyme kinetics

- increased dUMP levels

- decreased FdUMP accumulation

- decreased stability of ternary complex

- depletion of intracellular folates

- decreased polyglutamylation of folates

- recovery and enhanced enzyme synthesis

- gene amplification

- enzyme kinetic variants of the enzyme

C. Pharmacokinetic resistance

a. The drug does not reach the tumour

b. Disease state affects drug distribution

c. Increased elimination

Modified from [18]. resulted from $5 \mathrm{FU}$ treatment has also been studied in these systems $[4,16,24]$, but only after a single treatment and after a relatively short time interval from 2 to $48 \mathrm{~h}$ after drug administration. We studied the inhibition of thymidylate synthase in a murine colon tumour at several time points after weekly $5 \mathrm{FU}$, or leucovorin and $5 \mathrm{FU}$ therapy or after continuous infusion with 5FU. These data were related to the antitumour effect of these treatments on Colon 26, which was relatively resistant to $5 \mathrm{FU}$.

$\mathrm{Balb} / \mathrm{c}$ mice bearing Colon 26 were treated weekly with $100 \mathrm{mg} / \mathrm{kg} 5 \mathrm{FU}$ alone or with $50 \mathrm{mg} / \mathrm{kg}$ leucovorin followed after $1 \mathrm{~h}$ by $50 \mathrm{mg} / \mathrm{kg}$ leucovorin and $100 \mathrm{mg} / \mathrm{kg} 5 \mathrm{FU}$. This has been shown to be the most effective regimen to treat this tumour with leucovorin and 5FU [23]. Continuous infusions were given by implanting subcutaneous pellets, which delivered a dose of $10 \mathrm{mg} 5 \mathrm{FU} /$ mouse $/ 21$ days. The antitumour effect of these treatments was evaluated by the growth delay factor (GDF), reflecting the gain in tumour doubling times after treatment. After 4 weekly treatments, it was observed that leucovorin potentiated the antitumour effect of 5FU approximately 2- to 3fold in the Colon 26 tumour (GDF 1.2 versus 2.6) [14]. GDF of continuous infusion $5 \mathrm{FU}$ was 2.1 after 3 weeks [25].

Tumours from a different group of mice bearing Colon 26 were removed at several time points (ranging from 3 to 17 days) after initiation of treatment and used for enzymatic measurements. Thymidylate synthase inhibition was evaluated with two assays; a ligand-binding assay with $\left[6-{ }^{3} \mathrm{H}\right]-\mathrm{FdUMP}$ to determine the free binding sites of the enzyme for FdUMP; and the ${ }^{3} \mathrm{H}$ release assay to determine the catalytic activity (conversion of dUMP to dTMP) of thymidylate synthase [14]. Before the assays, a part of the tumour homogenate was processed separately in order to dissociate the thymidylate synthase ternary complexes formed during treatment. This enabled us to measure the total catalytic activity (TS-total) and the total number of FdUMP binding sites (TS-tot), and to compare these with the residual catalytic activity (TS-res) and with the apparently free FdUMP binding sites (TS-free) after therapy.

In non-treated tumours, the FdUMP binding and catalytic activity in Colon 26 were $125 \mathrm{pmol} / \mathrm{g}$ wet weight and $2324 \mathrm{pmol} /$ $\mathrm{mg}$ protein/h [14]. After one bolus injection, values decreased to $30 \%$ of control, using both assays. The extent and retention (at least 3 days) of the thymidylate synthase inhibition was comparable for $5 \mathrm{FU} /$ leucovorin compared with $5 \mathrm{FU}$ therapy alone. Complete inhibition of thymidylate synthase, as found in human tumours [5] and other murine tumours [24], was never obscrved in our murine tumours. After a week, recovery of thymidylate synthase was seen, but the TS-total levels in SFUtreated tumours tended to be higher than in the controls (Figure 2). After three treatment courses, the change in TStotal was more pronounced. Changes in thymidylate synthase were more easily detected with the dUMP assay than with the FdUMP binding assay. Treatment with $5 F U$ induced a 4-fold increase of TS-total catalytic activity in Colon 26, while TS-res was $70 \%$ of the TS-total activity (day 17). Treatment with leucovorin and $5 \mathrm{FU}$ resulted in an only 2 -fold increase of TStotal activity. The extent of thymidylate synthase inhibition after three treatment courses of leucovorin and 5FU (day 17) was similar to that after the first course (day 3 ). The high levels of TS-res implied that thymidylate synthase inhibition after several courses of 5FU treatment was less effective than at the first treatment, explaining the $5 \mathrm{FU}$ resistance of this tumour. The prevention of the increase in thymidylate synthase by leucovorin 


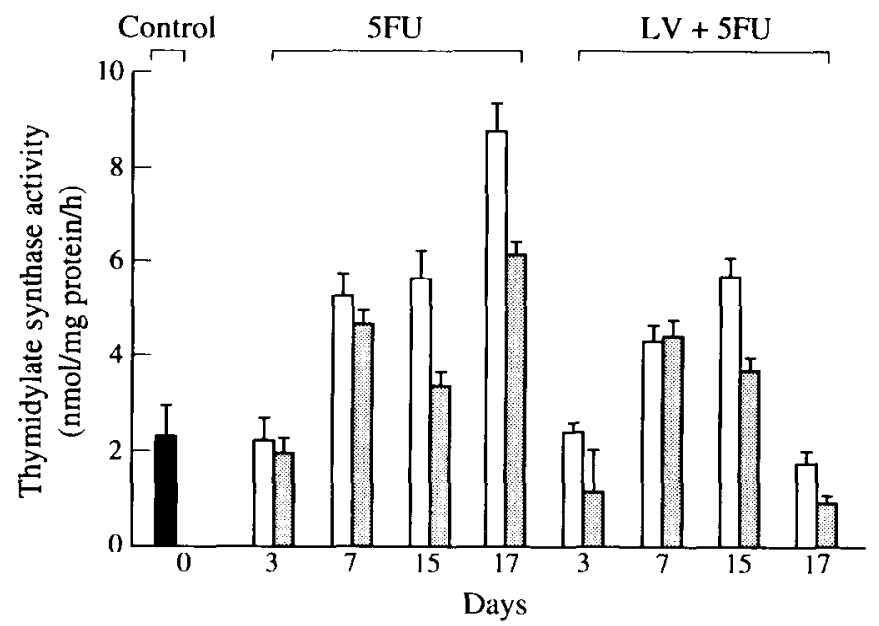

Figure 2. Inhibition and induction of thymidylate synthase in Colon 26 tumours treated with $5 F U$ and their prevention by leucovorin (LV). Catalytic activity of thymidylate synthase in Colon 26 was measured at $10 \mu M$ dUMP during three courses of single $5 F U$ or combined leucovorin and 5FU therapy. Values are means \pm S.D. $(n=3-5)$. Residual thymidylate synthase (圈) activity and total thymidylate synthase $(\square)$ activity were significantly higher in tumours from $5 F U$ treated mice, compared with leucovorin/5FU-treated tumours, on day $17(P<0.001)$. (From Van der Wilt et al. [14] with permission).

might explain the potentiating effect of leucovorin on $5 \mathrm{FU}$ antitumour activity in vivo on this tumour.

In the same murine colon tumour model [25], the tumours were initially sensitive to prolonged continuous administration of 5FU (GDF 2.1), but became resistant after approximately 10 days of the 21 day infusion. Although the $5 \mathrm{FU}$ infusion resulted in an initial inhibition of thymidylate synthase, regrowth of the tumour was associated with a rapid 3- to 4-fold increase in thymidylate synthase levels (both TS-total and TS-residual) at day 10 . Tissue $5 \mathrm{FU}$ levels remained comparable to those measured during the first days of the infusion.

The increase in thymidylate synthase levels may be the result of a FdUMP induced upregulation of thymidylate synthase protein synthesis. Under physiological conditions, the translation of the thymidylate synthase mRNA appears to be controlled by its end product, the thymidylate synthase protein [26]. However, treatment of cells or tumours leads to the formation of the stable thymidylate synthase ternary complex that may deregulate control synthesis of thymidylate synthase, resulting in an increased synthesis of thymidylate synthase protein. This can be detected on Western blots both as the native $38 \mathrm{kDa}$ protein and as the ternary complex (Figure 3). The 5FU induced increase could be prevented not only by interferon- $\gamma$ [27] but also by leucovorin (Figure 2). These mechanisms probably play a role in the observed enhancement of the sensitivity to 5FU and may reverse resistance to $5 F U$. It is not yet understood how leucovorin interacted in the process of thymidylate synthase increase.

\section{FU-INDUCED INHIBITION OF THYMIDYLATE} SYNTHASE IN PATIENTS

Inhibition of thymidylate synthase in tumours from 47 patients has been studied in biopsy specimens obtained during surgery at several time points (varying from 1 to $72 \mathrm{~h}$ ) after administration of a therapeutic dose of $5 F U\left(500 \mathrm{mg} / \mathrm{m}^{2}\right.$ as an i.v. bolus) [5]. In tumour samples from patients obtained within a few hours of drug administration, inhibition of thymidylate

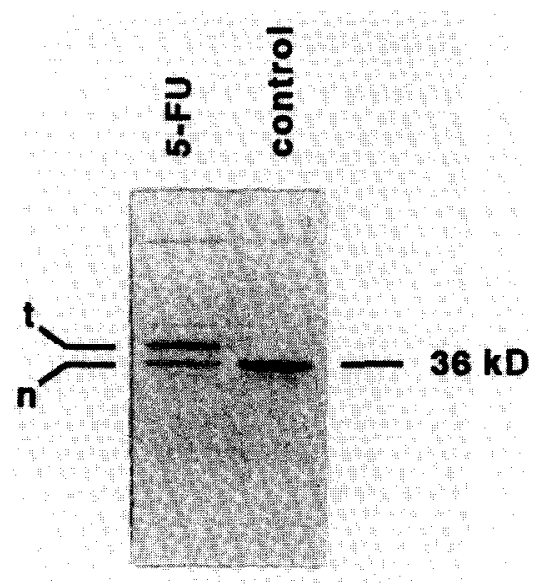

Figure 3. Induction of thymidylate synthase levels by treatment of cells with a $50 \%$ growth-inhibitory concentration of $5 F U$ as shown by Western blotting using a polyclonal antibody against TS (kindly provided by Dr G. W. Aherne, Sutton, U.K. [30]); the $36 \mathrm{kDa}$ band shows the native enzyme (n); the higher molecular weight band ( $t$ ) is the ternary complex formed by FdUMP-thymidylate synthase and $\mathrm{CH}_{2}-\mathrm{THF}$.

synthase was almost complete, although a large interindividual variation was observed (Table 2 ). In samples from patients obtained 1 or 2 days after drug administration, inhibition of thymidylate synthase was clearly reduced compared to the $2 \mathrm{~h}$ samples. After 1 and 2 days, thymidylate synthase activity was still 27 and $49 \%$, respectively, of total thymidylate synthase levels. This total uninhibited level of thymidylate synthase in tumour samples was significantly higher at $23 \mathrm{~h}$ than that at 2 and $45 \mathrm{~h}$. The large variation in the total level of thymidylate synthase in these treated tumours was comparable to that found in untreated patients [28].

In 14 patients, we were able to study both primary tumours and liver metastases. No consistent difference in thymidylate synthase levels was found between the tumour sites, and in half the patients thymidylate synthase activity was higher in the primary tumour, while in other patients activity was higher in the liver metastases. The concentration of FdUMP, the active metabolite of $5 F U$, showed a time-dependent pattern, with the highest levels observed shortly after drug administration and decreasing to below detection limits $(<10 \mathrm{pmol} / \mathrm{g}$ tissue $)$ in most samples after $48 \mathrm{~h}$ [13]

In an attempt to enhance the inhibition of thymidylate synthase, leucovorin $\left(2 \mathrm{~h}\right.$ infusion at $500 \mathrm{mg} / \mathrm{m}^{2}$ with $5 F U$ injected midway infusion) was administered to a subgroup of 11 patients. Thymidylate synthase inhibition after 2 days was much more pronounced in samples from patients receiving leucovorin-5FU administration than after single agent 5FU (Figure 4). In patients who received a low dose of leucovorin $\left(25 \mathrm{mg} / \mathrm{m}^{2}\right)$ just before the $5 \mathrm{FU}$ bolus, thymidylate synthase inhibition was reduced compared with the high dose of leucovorin [29].

\section{THYMIDYLATE SYNTHASE INHIBITION IN RELATION TO RESPONSE}

In 19 patients who were treated with single agent $5 F U$ as a hepatic arterial infusion and 8 patients who were treated with 5FU systemically (with or without leucovorin), we evaluated whether the total level and inhibition of thymidylate synthase correlated with the outcome of therapy (Figure 5). In samples of patients who had received a test dose of 5FU only, a 
Table 2. Levels of thymidylate synthase in biopsy specimens from tumours after administration of $5 F U$ with or without leucovorin

\begin{tabular}{|c|c|c|c|c|c|}
\hline \multirow[b]{2}{*}{ Time $(h)$} & \multirow[b]{2}{*}{ Drugs } & \multicolumn{2}{|c|}{ Catalytic activity (pmol/h/mg protein) } & \multicolumn{2}{|c|}{ FdUMP binding (fmol/mg protein) } \\
\hline & & TS-Total & TS-Res & TS-tot & TS-Free \\
\hline 2 & $5 \mathrm{FU}$ & $21(0-104)$ & $11(0-39)$ & $58 \quad(33-976)$ & $0(0-376)$ \\
\hline 23 & $5 \mathrm{FU}$ & $53^{*}(0-621)$ & $32(0-372)$ & $120^{*}(0-759)$ & $22(0-296)$ \\
\hline 45 & $5 \mathrm{FU}$ & $37 \quad(0-178)$ & $30(0-152)$ & $64(0-314)$ & $23(0-140)$ \\
\hline 45 & LV-5FU & $31(4-170)$ & $13(0-19)$ & $(0-383)$ & $22(0-101)$ \\
\hline
\end{tabular}

Biopsy specimens were taken at the indicated time intervals after drug administration. TS catalytic activity was measured at $1 \mu \mathrm{M}$ dUMP. Values are medians of 13-19 biopsy specimens; the range is indicated in parentheses. *Significantly different from values at 2 and $45 \mathrm{~h}(P<0.02$; two-tailed Mann-Whitney $\mathrm{U}$ test $)$. Data are from Peters et al. [5]

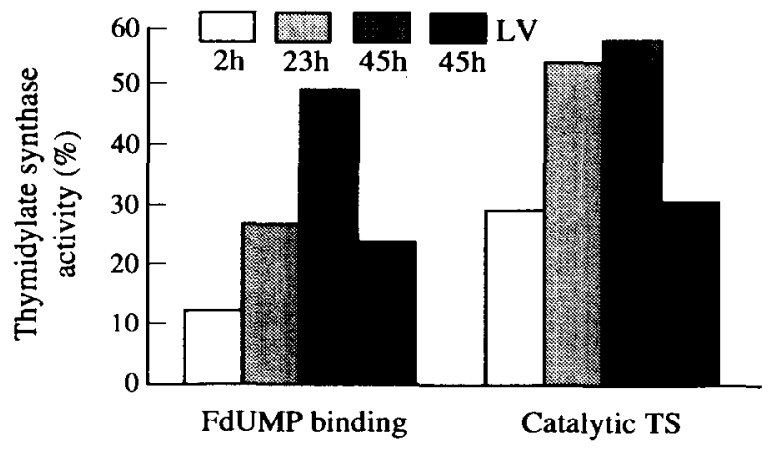

Figure 4. Inhibition of thymidylate synthase after administration of a test dose of 5FU or 5FU combined with leucovorin (LV) at $2-45 \mathrm{~h}$. Values represent means from $10-17$ samples (S.E.M. was $<10 \%$ ). The means were calculated from the separate samples as the ratio between TS-free/TS-tot $\times 100 \%$ for the FdUMP binding and between TS-res/TS-total $\times 100 \%$ for the TS catalytic activity at $10 \mu \mathrm{M}$ dUMP. The leucovorin-5FU data were significantly different from the $45 \mathrm{~h}$ 5FU at the level; $0.001<P<0.01$ (FdUMP binding); (Student's $t$-test). Using the Mann-Whitney U test, the 45 h $5 F U$ data (both assays) were significantly different from the leucovorin-5FU data $(0.002<P<0.02)$ and from the 2 h $5 F U$ data $(P<0.002)$ (from Peters et al. [5], with permission).

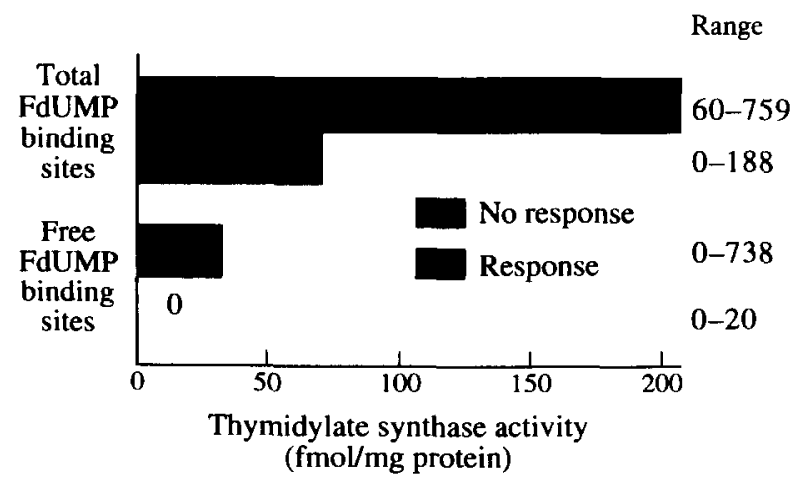

Figure 5. Relation between thymidylate synthase activity as evaluated with the FdUMP binding assay (TS-tot;TS-free) and response (partial response; 9 patients) and no response (stable disease and progressive disease; 9 patients) after treatment with single agent $5 \mathrm{FU}$. The ranges of thymidylate synthase activities are also shown in the right-hand column. The differences in thymidylate synthase levels between the patients in the response and no response groups were significant at the level $P=0.0123$ (TS-tot) and $P=0.0071$ (TS-free) (modified from Peters et al. [5]). high number of total FdUMP binding sites and a high total thymidylate synthase catalytic activity were associated with no response, whereas a low thymidylate synthase activity was associated with a partial response. However, when the patients who received leucovorin-5FU as test drugs were included, the difference was non-significant (data not shown). Almost no free FdUMP binding sites were detected in responding patients who had received only $5 F U$ as a test drug, while measurable binding was observed in non-responding patients (Figure 5). It was concluded that a combination of either high FdUMP binding ( $>100 \mathrm{fmol} / \mathrm{mg}$ protein), total catalytic activity $(>90 \mathrm{pmol} / \mathrm{h} /$ mg protein), or a poor inhibition with either assay $(<90 \%)$, were related to no response. In addition to this study, other studies have suggested that tumours from patients responding to 5FU show greater inhibition of thymidylate synthase than tumours of patients with progressive disease [3-5]. In breast cancer patients, binding of FdUMP and the effect of $\mathrm{CH}_{2}-\mathrm{THF}$ decreased during the development of resistance [4]. These results demonstrate that analysis of biochemical parameters in tumour biopsies obtained at both short and long time intervals after $5 \mathrm{FU}$ administration gives valuable information about the in vivo mechanism of action of the drug in the tumours of patients.

\section{PROGNOSTIC VALUE OF THYMIDYLATE SYNTHASE}

The above-mentioned studies were performed using tumour samples obtained from patients after administration of a test dose of 5FU. However, this approach is not always possible in a routine setting. Traditionally, thymidylate synthase levels have been measured by determining the number of FdUMP binding sites or by measurement of the conversion of dUMP to dTMP. More recently, new methods have become available, such as ELISA assays for thymidylate synthase [30, 31], immunohistochemistry $[7,32,33]$ or semi-quantitative PCR $[34,35]$. However, for each of these methods, it is still not clear whether thymidylate synthase is really related to the sensitivity to SFU. In a panel of 19 cell lines from various histological origins $(5$ head and neck cancer, 6 breast and 8 from cancer of the digestive tract), Beck and associates [36] observed a relatively poor relationship between TS activity and sensitivity to SFU $\left(r^{2}=0.22\right)$, whereas, in our hands, a similar relationship $\left(r^{2}=0.27\right)$ was observed in a panel of 14 cell lines with a different histological origin (colon cancer and head and neck cancer) [37]. This means that other factors play a role in the sensitivity to $5 \mathrm{FU}$, although thymidylate synthase is probably one of the most important. 

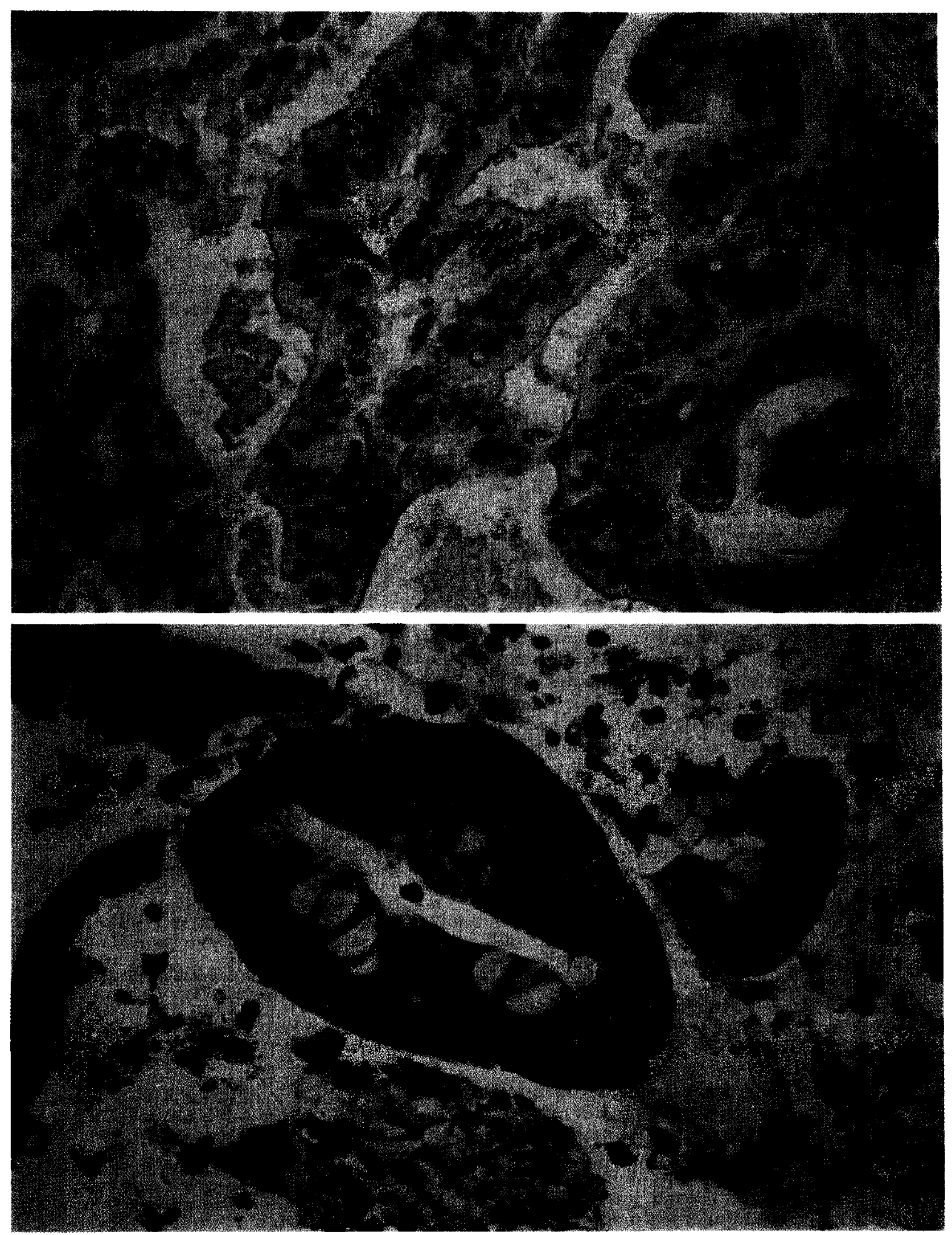

Figure 6. Immunohistochemical staining of thymidylate synthase of colon tumours from patients. One cross-section shows a low level of thymidylate synthase $(A$; staining intensity rated at + ) and a patient with a high level (B; staining intensity rated as +++ ). The polyclonal antibody was kindly donated by Dr G.W. Aherne, Sutton, U.K. [30], and was used at a 100-fold dilution. Magnification $\times 500$; the marker in the figure represents $20 \mu \mathrm{m}$. 


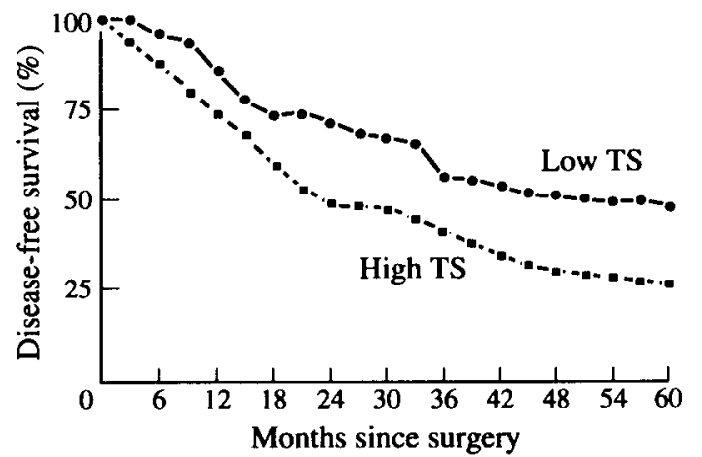

Figure 7. Correlation of the thymidylate synthase level with diseasefree survival in patients with rectal cancer. The thymidylate synthase staining intensity was compared with the percentage of patients who are disease-free after 5 years. The log-rank test adjusted for Dukes' stage and treatment group were used to test the difference between life-table distributions (from Johnston and associates [7], with permission).

Using an ELISA assay for thymidylate synthase, Johnston and associates [31] observed a good relationship between FdUMP binding activity and ELISA results, as well as between ELISA results and sensitivity to $5 \mathrm{FU}$. Within several panels of cell lines from the same histological origin, we also observed a good relationship between thymidylate synthase enzyme activity and immunohistochemical staining for thymidylate synthase of cellular cytospins [33]. Initial immunohistochemical staining of crosssections of frozen tumour samples demonstrated a intense cytosolic staining in tumours with a high thymidylate synthase activity, but a faint staining in tumours with a low thymidylate synthase activity (Figure 6). The numbers are too small for a statistical evaluation of a relationship with the response to $5 \mathrm{FU}$ therapy. Similarly, we observed a good relationship between thymidylate synthase activity and expression of thymidylate synthase mRNA as determined using a semi-quantitative RTPCR assay [35].

Recent studies have also demonstrated that either thymidylate synthase immunohistochemical staining or quantitation of thymidylate synthase mRNA expression can be used to predict the outcome of chemotherapy. Johnston and colleagues [7] evaluated the thymidylate synthase levels in primary rectal tumours from 294 patients, enrolled in an adjuvant therapy protocol comparing surgery alone with surgery with chemotherapy consisting of methyl-CCNU, 5FU and vincristine (MOF). Thymidylate synthase expression appeared to be a treatment-independent prognostic factor. The 5-year disease-free survival of patients with tumours with a low intensity staining (grading 0 and 1) was $49 \%$, while that of patients with a high intensity staining (grading 2 and 3) was $27 \%(P<0.01)$ (Figure 7$)$. Thymidylate synthase expression was also correlated with the benefit of chemotherapy, but only in patients with a high-intensity staining. The 5-year disease-free survival in the group receiving MOF adjuvant cliemotherapy was $38 \%$ while in patients with surgery alone it was $17 \%(P<0.01)$; in the group of patients with a lowintensity staining for thymidylate synthase, these values were 36 and $43 \%$, respectively. Similar differences were observed for overall survival. In a prospective study performed in the Netherlands, initial data from 60 patients demonstrate 17 patients have a faint staining (rated as + ), 29 patients have intermediate staining (rated as ++ ) and 14 patients have intense staining (rated as +++ ). No data on outcome of therapy are available as yet [38].
More recent evidence on the prospective value of thymidylate synthase has been obtained in patients with gastric cancer who received $5 F U$ therapy $[39,40]$. Thymidylate synthase mRNA expression was quantitated using a RT-PCR assay. All patients above a certain threshold expression level progressed on chemotherapy, while patients who responded had a significantly lower thymidylate synthase expression level.

\section{CONCLUSION}

Both insufficient thymidylate synthase inhibition and high intrinsic levels of thymidylate synthase are related to several forms of resistance to therapy with 5FU or with leucovorin and $5 F U$. High thymidylate synthase levels may also be associated with poor prognosis of chemotherapy. This information can be used to design more effective chemotherapy regimens, such as the use of more specific folate-based thymidylate synthase inhibitors [41].

1. Pinedo HM, Peters GJ. 5-Fluorouracil: biochemistry and pharmacology. F clin Oncol 1988, 6, 1653-1664.

2. Peters GJ, Jansen G. Resistance to antimetabolites. In Schilsky RL, Milano GA, Ratain MJ, eds. Principles of Cancer Drug Pharmacology. New York, Marcel Dekker, 1995, in press.

3. Spears CP, Gustavsson BG, Mitchell MS, et al. Thymidylate synthase inhibition in malignant tumors and normal liver of patients given intravenous 5-fluorouracil. Cancer Res 1984, 44, 4144 4150.

4. Swain SM, Lippman ME, Egan EF, Drake JC, Steinberg SM, Allegra CJ. Fluorouracil and high-dose leucovorin in previously treated patients with metastatic breast cancer. 7 clin Oncol 1989, 7 , $890-899$.

5. Peters GJ, Van der Wilt CL, Van Groeningen CJ, Meijer S, Smid $\mathrm{K}$, Pinedo HM. Thymidylate synthase inhibition after administration of 5-fluorouracil with or without leucovorin; implications for treatment with 5-fluorouracil. $7 \mathrm{clin}$ Oncol 1994, 12, $2035-2042$.

6. Spears CP, Gustavsson BG, Berne M, Frosing R, Bernstein L, Hayes AA. Mechanisms of innate resistance to thymidylate synthase inhibition after 5-fluorouracil. Cancer Res 1988, 48, 5894-5900.

7. Johnston PG, Fisher ER, Rockette HE, et al. The role of thymidylate synthase expression in prognosis and outcome of adjuvant chemotherapy in patients with rectal cancer. $\mathcal{F}$ clin Oncol 1994, 12, 2640-2647.

8. Peters GJ, Laurensse E, Steinbusch HWM, et al. Development, characterization and application of an antibody against 5-fluoro-2'deoxy-5'-monophosphate, the active metabolite of 5-fluorouracil. Anticancer Res 1993, 13, 835-840.

9. Priest DG, Ledford SE, Doig MT. Increased thymidylate synthet ase in 5-fluorodeoxyuridine resistant cultured hepatoma cells. Biochem Pharmac 1980, 29, 1549-1553.

10. Yin MB, Zakrzewski SF, Hakala MT. Relationship of cellular folate cofactor pools to the activity of 5-fluorouracil. Mol Pharmac 1983, 23, 190-197.

11. Berger SH, Hakala MT. Relationship of dUMP and FdUMP pools to inhibition of thymidylate synthase by 5 -fluorouracil. MolPharmac $1984,25,303-309$.

12. Berger SH, Barbour KW, Berger FG. A naturally occurring variation in thymidylate synthase structure is associated with a reduced response to 5-fluoro-2'-deoxyuridine in a human colon tumor cell line. Mol Pharmac 1988, 34, 480-484.

13. Peters GJ, Lankelma J, Kok RM, et al. Prolonged retention of high concentrations of 5-fluorouracil in human and murine tumors as compared with plasma. Cancer Chemother Pharmac 1993, 31, 269-276.

14. Van der Wilt CL, Pinedo HM, Smid K, Peters GJ. Elevation of thymidylate synthase following 5-fluorouracil treatment is prevented by the addition of leucovorin in murine colon tumors. Cancer Res 1992, 52, 4922-4928.

15. Van der Wilt CL, Braakhuis BJM, Pinedo HIM, De Jong M, Smid K, Peters GJ. Addition of leucovorin in modulation of 5-fluorouracil with methotrexate: potentiating or reversing effect? Int $\mathcal{J}$ Cancer $1995,61,672-678$.

16. Houghton JA, Torrance PM, Radparvar S, Williams LG, Houghton $\mathrm{PJ}$. Binding of 5-fluorodeoxyuridylate to thymidylate synthase in 
human colon adenocarcinoma xenografts. Eur $\mathcal{f}$ Cancer Clin Oncol $1986,22,505-510$.

17. Wang FS, Aschele C, Sobrero A, Chang YM, Bertino JR. Decreased folylpolyglutamate synthetase expression: a novel mechanism of fluorouracil resistance. Cancer Res 1993, 53, 3677-3680.

18. Peters GJ, Van Groeningen CJ. Clinical relevance of biochemical modulation of 5-fluorouracil. Ann Oncol 1991, 2, 469-480.

19. Van der Wilt CL, Pinedo HM, De Jong M, Peters GJ. Effect of folate diastereoisomers on the binding of 5-fluoro-2'-deoxyuridine5 '-monophosphate to thymidylate synthase. Biochem Pharmac 1993, 45, 1177-1179.

20. Jenh CH, Geyer PK, Baskin F, Johnson LF. Thymidylate synthase gene amplification in fluorodeoxyuridine-resistant mouse cell lines. Mol Pharmac 1985, 28, 80-85.

21. Clark JL, Berger SH, Mittelman A, Berger FG. Thymidylate synthase overproduction gene amplification in a colon tumor resistant to fluoropyrimidine chemotherapy. Cancer Treat Rep 1987, 71, 261-265.

22. Mini E, Trave F, Rustum YM, Bertino JR. Enhancement of the antitumor effects of 5-fluorouracil by folinic acid. Pharmac Ther $1990,47,1-19$.

23. Nadal JC, Van Groeningen CJ, Pinedo HM, Peters GI. Schedule dependency of in vivo modulation of 5-fluorouracil by leucovorin and uridine in murine colon carcinoma. Invest New Drugs 1989, 7, $163-172$.

24. Spears CP, Shahinian AH, Moran RG, Heidelberger C, Corbett TH. In vivo kinetics of thymidylate synthetase inhibition in FUrasensitive and -resistant murine colon adenocarcinomas. Cancer Res $1982,42,450-456$.

25. Codacci-Pisanelli G, Van der Wilt CL, Pinedo HM, et al. Antitumour activity, toxicity and inhibition of thymidylate synthase of prolonged administration of 5-fluorouracil in mice. Eur 7 Cancer 1995 , in press

26. Chu E, Koeller D, Casey J, et al. Autoregulation of human thymidylate synthase messenger RNA translation by thymidylate synthase. Proc Natl Acad Sci USA 1991, 88, 8977-8981.

27. Chu E, Koeller DM, Johnston PG, Zinn S, Allegra CJ. Regulation of thymidylate synthase in human colon cancer cells treated with 5-fluorouracil and interferon-gamma. Mol Pharmac 1993, 43, 527-533.

28. Peters GJ, Van Groeningen CJ, Laurensse EJ, Pinedo HM. Thymidylate synthase from untreated human colorectal cancer and colonic mucosa: enzyme activity and inhibition by 5-fluoro-2'-deoxyuridine-5'-monophosphate. Eur $\mathcal{F}$ Cancer 1991, 27, 263-267.

29. Peters GJ, Hoekman K, Van Groeningen CJ, et al. Potentiation of 5-fluorouracil induced inhibition of thymidylate synthase in human colon tumors by leucovorin is dose dependent. In Ayling JE, Nair MG, Baugh CM, eds. Ckemistry and Biology of Pteridines and Folates. New York, Plenum, 1993. Adv Exp Med Biol 1993, 338, 613-616.
30. Aherne GW, Hardcastle A, Newton R. Measurement of human thymidylate synthase (hTS) in cell lines using ELISA. Ann Oncol 1992, 3, (suppl. 1), 77 .

31. Johnston PG, Drake JC, Steinberg SM, Allegra CJ. Quantitation of thymidylate synthase in human tumors using an ultrasensitive enzyme-linked immunoassay. Biochem Pharmac 1993, 45, 2483-2486.

32. Johnston P, Liang C, Henry S, Chabner B, Allegra C. Production and characterization of monoclonal antibodies that localize human thymidylate synthase in the cytoplasm of human cells and tissue. Cancer Res 1991, 51, 6668-6676.

33. Van der Wilt CL, Smid K, Aherne GW, Pinedo HM, Peters GJ. Evaluation of immunohistochemical staining and activity of thymidylate synthase in cell lines. In Ayling JE, Nair MG, Baugh $\mathrm{CM}$, eds. Chemistry and Biology of Pteridines and Folates. New York, Plenum, 1993. Adv Exp Med Biol 1993, 338, 605-608.

34. Horikoshi T, Danenberg D, Stadbauer THW, et al. Quantitation of thymidylate synthase, dihydrofolate reductase, and DT-diaphorase gene expression in human tumors using the polymerase chain reaction. Cancer Res 1992, 51, 108-116.

35. Freemantle SJ, Lunec J, Van der Wilt CL, et al. Polymerase chain reaction quantification of thymidylate synthase (TS) mRNA levels in tumour samples of patients recently treated with 5-fluorouracil (5-FU) \pm leucovorin (LV). Proc Am Assoc Cancer Res 1993, 34, 348.

36. Beck A, Etienne $M C$, Chéradame $S$, et al. A role for dihydropyrimidine dehydrogenase and thymidylate synthase in tumor sensitivity to fluorouracil. Eur $\mathcal{F}$ Cancer 1994, 10, 1517-1522.

37. Peters GJ, Van der Wilt CL, Van Groeningen CJ. Predictive value of thymidylate synthase and dihydropyrimidine dehydrogenase. Eur f Cancer 1994, 10, 1408-1411.

38. Van Triest B, Telleman F, Pinedo HM, et al. Thymidylate synthase levels in patients with colorectal cancer. Proc Ist Int Congr From Gene to Cure: Colorectal Cancer. 1995, Amsterdam.

39. Lenz HJ, Leichman C, Danenberg P, et al. Thymidylate synthase (TS) gene expression predicts response of primary gastric cancer (GC) to 5-fluorouracil (SFU)-leucovorin (LV)-cisplatin (DDP). Proc Am Soc Clin Oncol 1993, 12, 199.

40. Leichman L, Lenz H-J, Leichman CG, et al. Quantitation of intratumoral thymidylate synthase expression predicts for resistance to protracted infusion 5-fluorouracil and weekly leucovorin in disseminated colorectal cancers: preliminary report from an ongoing trial. Eur $\mathcal{f}$ Cancer 1995, 31 A, 1306-1310.

41. Jackman AL, Farrugia D, Gibson W, et al. ZD1694 (Tomudex): a new thymidylate synthase inhibitor with activity in colorectal cancer. Eur F Cancer 1995, 31A, 1277-1282.

Acknowledgement-Supported by the Dutch Cancer Society by grants IKA VU 92-88 and 93-627. 